\title{
Dog Owners' Knowledge about Rabies and Other Factors That Influence Canine Anti-Rabies Vaccination in the Upper East Region of Ghana
}

\author{
Baba Awuni ${ }^{1}$, Elvis Tarkang ${ }^{2}$, Emmanuel Manu 2,*(D), Hubert Amu ${ }^{2}$ (D), \\ Martin Amogre Ayanore ${ }^{3}{ }^{\mathbb{D}}$, Fortress Yayra Aku ${ }^{4}$, Sorengmen Amos Ziema ${ }^{1} \mathbb{D}$, \\ Samuel Adolf Bosoka ${ }^{1}$, Martin Adjuik ${ }^{4}$ and Margaret Kweku 1,4 \\ 1 School of Public Health, University of Health and Allied Sciences, Ho PMB 31, Volta Region, Ghana \\ 2 Department of Population and Behavioural Sciences, School of Public Health, University of Health and \\ Allied Sciences, Ho PMB 31, Volta Region, Ghana \\ 3 Department of Family and Community Health, University of Health and Allied Sciences, Ho PMB 31, \\ Volta Region, Ghana \\ 4 Department of Epidemiology and Biostatistics, University of Health and Allied Sciences, Ho PMB 31, \\ Volta Region, Ghana \\ * Correspondence: emanu@uhas.edu.gh; Tel.: +233-(0)5-5042-9899
}

Received: 14 May 2019; Accepted: 5 August 2019; Published: 18 August 2019

\begin{abstract}
Background: Human rabies, often contracted through dog bites, is a serious but neglected public health problem in the tropics, including Ghana. Due to its high fatality rate, adequate knowledge and vaccination of domestic dogs against the disease are very crucial in reducing its burden. We examined dog owners' knowledge level on rabies and factors that influenced anti-rabies vaccination of dogs in the Upper East Region of Ghana. Methods: This descriptive cross-sectional study was conducted among 260 randomly sampled dog owners in six communities from six Districts using a multistage sampling technique, in the Upper East Region of Ghana. An interviewer-administered questionnaire was used to collect data from the respondents. Descriptive and inferential analyses were done using STATA 14.1. Results: While knowledge about rabies was 199 (76.5\%), that about anti-rabies vaccination was $137(52.7 \%)$. District of residence $\left(\chi^{2}=112.59, p<0.001\right)$, $\operatorname{sex}\left(\chi^{2}=6.14, p=0.013\right)$, education $\left(\chi^{2}=20.45, p<0.001\right)$ as well as occupation $\left(\chi^{2}=11.97, p=0.007\right)$ were significantly associated with rabies knowledge. District of residence $\left(\chi^{2}=57.61, p<0.001\right)$, Educational level $\left(\chi^{2}=15.37, p=0.004\right)$, occupation $\left(\chi^{2}=11.66, p=0.009\right)$, religion $\left(\chi^{2}=8.25, p=0.016\right)$ and knowledge on rabies $\left(\chi^{2}=42.13, p<0.001\right)$ were also statistically associated with dog vaccination against rabies. Dog owners with good knowledge on rabies for instance, were more likely to vaccinate their dogs against rabies compared to those with poor knowledge [AOR $=1.99(95 \%$ CI: 0.68, 5.86), $p=0.210]$. Dog owners with tertiary level of education were also 76.31 times more likely $(95 \% \mathrm{CI}$ : $6.20,938.49, p=0.001$ ) to have good knowledge about rabies compared to those with no formal education. Conclusions: Dog owners in the Upper East Region of Ghana had good knowledge about rabies. This, however, did not translate into correspondingly high levels of dog vaccination against the disease. Rabies awareness and vaccination campaigns should, therefore, be intensified in the region, especially among the least educated and female dog owners.
\end{abstract}

Keywords: dog bite; dog owners; rabies; knowledge; vaccination; upper east region; Ghana

\section{Introduction}

Dog bites are considered a public health concern worldwide as they cause physical injury, psychological trauma, post-traumatic stress, and sometimes death resulting from rabies infection $[1,2]$. 
Rabies, a neglected tropical disease, is a neuro-invasive disease caused by Rhabdovirus, commonly transmitted from the saliva of some infected warm-blooded animals such as domestic dogs and cats, through bites or other forms of contact [3,4]. About $99 \%$ of human rabies cases are transmitted by domestic dogs [5]. Though rabies is a vaccine-preventable viral zoonosis, it remains a critical public health issue, with about 59,000 human deaths reported globally each year, with Asia and Africa accounting for more than $95 \%$ of these deaths [6,7].

Ghana is one of the countries on the African continent where rabies remains endemic [8]. Rabies is a public health concern in Ghana due to a large stray dog population across the country [9]. Despite efforts to reduce the prevalence of rabies in the country, substantial numbers of new cases are recorded annually. From the year 2000 to 2004, a total of 123 clinically confirmed rabies cases were reported [10]. Between January 2009 and July 2011, 25 rabies cases resulting from canine bites were recorded in the country, marking a significant reduction in the number of rabies deaths in the country [10]. However, as a result of erratic rabies prevention strategies; thus inconsistent rabies prevention measures, rabies cases peaked up again by the year 2016, where 64 human rabies cases were recorded [10]. This is because although the Ghana government embarked on a campaign to vaccinate dogs against rabies across the country [11] the campaign was not sustained and has been stopped since 1994 due to lack of sustainable funding and support. Since then, individual dog owners are expected to use their personal income to vaccinate their dogs against rabies either by the government or private veterinary officers [12]. Although there is no documented standardized pricing for anti-rabies vaccination of dogs in Ghana, information from the veterinary division of the Ministry of Agriculture revealed that a shot of anti-rabies vaccine can cost up to $\$ 4$ per dog. This places huge financial burden on dog owners, especially in a country where $23.4 \%$ of the population live on less than $\$ 1$ a day [13]. Hence, increased financial burden, coupled with the sporadic nature of anti-rabies vaccine and post exposure prophylaxis supply $[12,14]$ has exacerbated the risk of potential rabies outbreak, therefore, the need for dog owners to be knowledgeable about rabies and the need to vaccinate dogs against rabies.

The Upper East Region is the only known region out of the 10 regions in the country where dogs are sold in open markets for human consumption [15], in addition to regular dog keeping. However, these dogs are not properly confined, which results in persistent straying of dogs [16]. There is therefore, the likelihood of frequent dog bites, which could lead to the possibility of high number of rabies cases as the percentage of dogs vaccinated against the disease remains unknown [17]. Rabies affects the central nervous system, with almost $100 \%$ case fatality rate [8]. As such, knowledge of dog owners on rabies, anti-rabies vaccination coverage, and factors that underline anti-rabies vaccination coverage in a region where dogs are sold on the open market for consumption, are not confined and also rely on individual dog owners to fund anti-rabies dog vaccination, could be useful prerequisites in developing effective rabies control strategies in the Upper East Region and Ghana as a whole. The current study, therefore, ascertained dog owners' knowledge on rabies and factors influencing anti-rabies vaccination by dog owners in the Upper East Region of Ghana.

\section{Methods}

\subsection{Setting}

Ghana is a country in the Western part of Africa with 10 administrative regions; Greater Accra, Western, Eastern, Central, Volta, Ashanti, Brong Ahafo, Northern, Upper West, and Upper East regions. The Upper East Region is located in the North-Eastern corner of the country and between longitudes $0^{\circ}$ and $1^{\circ}$ West and latitudes $100^{\circ} 30^{\prime \prime} \mathrm{N}$ and $110 \mathrm{~N}$ with Bolgatanga as its capital. It has two international boundaries; Burkina Faso to the North and the Republic of Togo to the East; and also shares borders with the Northern and Upper West Regions of Ghana [18]. The 2010 Population and Housing Census of Ghana puts the population of the Region at 1,046,545 [18]. Figure 1 presents a map of the study setting. 


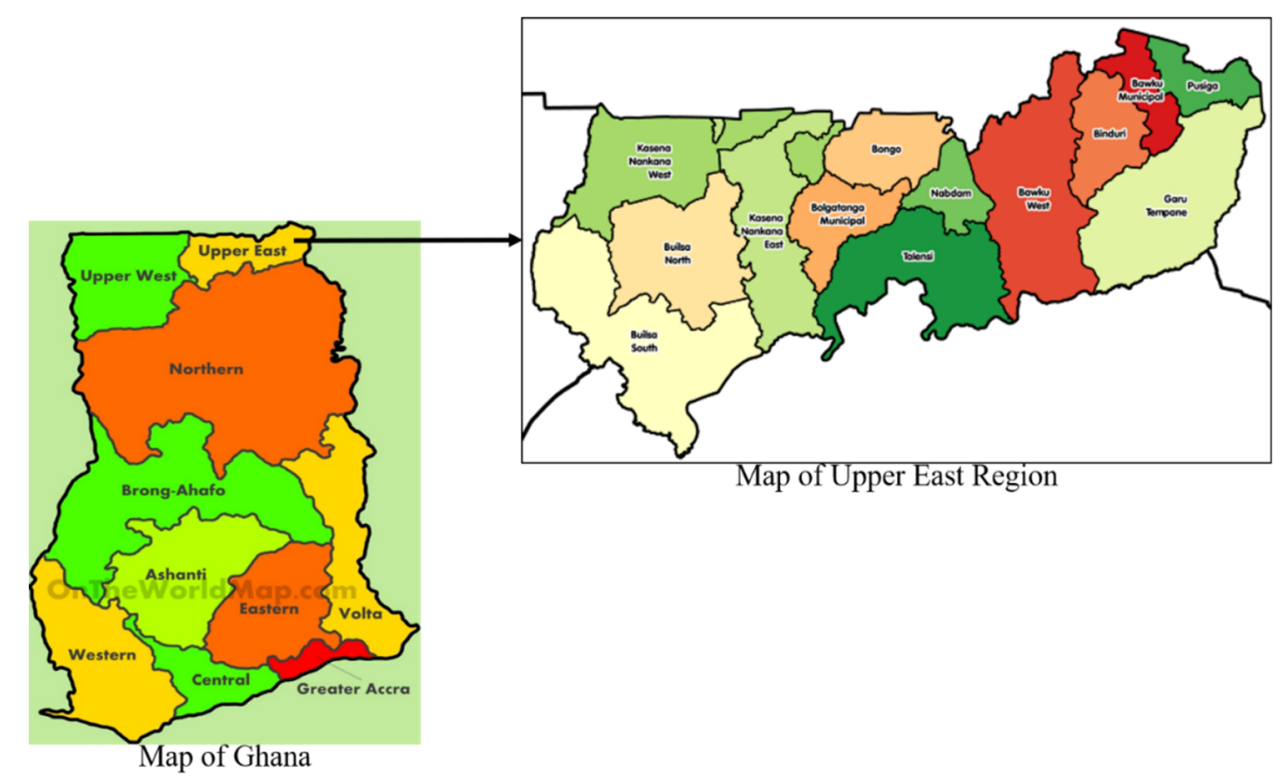

Figure 1. Study setting.

\subsection{Study Design}

This descriptive cross-sectional study was conducted in April 2017 among dog owners in six communities from six districts in the Upper East Region of Ghana. The cross-sectional nature of the study aided to obtain the needed information from the respondents at a single point in time although recruitment of respondents took place over a period of time [19].

Study Population and Sampling

The source population comprised all adult (18 years and above) dog owners within the Upper East Region of Ghana, who had resided in the region for a minimum of 6 months. A representative sample of 260 respondents from six selected districts with an anticipated attrition (turnover) rate of 5\%, based on experiences drawn from the pilot study [20], was used for the study. This was calculated using the formula $n=Z^{2} \times P(1-P) / E^{2}[21]$.

A three-stage sampling technique was used for the selection of the respondents from six out of the 15 districts in the region. The first stage consisted of selection of six Districts from the fifteen districts in the region. This was done by randomly selecting from the list of districts, using the simple random (lottery) sampling technique. With the lottery approach, the names of the districts were written on pieces of paper, put in a container, thoroughly shaken and the first district selected. The process was then repeated until the 6th district was selected. The second stage was the selection of communities per district which made use of the same method adopted in selecting the districts. The selected communities were Sumburungu in Bolgatanga Municipality, Binaba in Bawku West District, Gore in Bongo District, Abiliyire No. 1 in Builsa North District, Wiidi in Bawku Municipality and Natugnia in Kassena Nankana Municipality.

The final stage involved the selection of households and dog owners. Since a list of households and dog owners were not available, households were selected per community based on the WHO cluster survey technique [22]. A central location in each town was first identified. A starting point was then randomly selected from the centre using the bottle method. With this, a bottle was spun and the direction where the mouth of the bottle settled was selected. The research team then walked in the selected direction, counting the number of houses until the edge of the village was reached. Using a systematic sampling approach, the sampling fraction of 5 was selected from a list of total number of houses counted. Each 5th house from the centre along the chosen direction was then chosen. In households where there were more than one dog owners, and were both willing to participate, 
one dog owner was selected by ballot. Households with no dog owners were skipped. The next household with a dog owner was chosen to replace the skipped household. A pre-tested questionnaire was used by trained research assistants for data collection.

\subsection{Data Analysis}

Data collected were analysed using STATA 14.1 (StataCorp LLC, College Station, TX, USA). Respondents' knowledge on rabies was assessed by asking a set of six questions on rabies relating to its causes, symptoms and modes of transmission, adapted from Assefa et al. [23]. The questions asked were: Do dogs carry rabies virus? Can a dog transmit rabies to humans through biting or scratching? Can a dog transmit rabies to humans through licking of open wound? Are aggression, madness and paralysis all signs of rabies infection in humans? Can rabies be prevented? Is there the need to go to the hospital after being bitten by a dog? The questions were chosen based on their ease of understanding to respondents during piloting as well as their acceptable reliability (Cronbach's alpha of 0.94) in measuring respondents' level of knowledge on rabies, as per Taber's interpretation [24].

In determining whether respondents had good or poor knowledge on rabies, the median score of the six questions, 4, was used. A score equivalent to the median or above was rated as good knowledge while below that was considered as poor knowledge [25]. Chi-square tests were conducted to determine the relationship between socio-demographic characteristics and knowledge on rabies. Binary logistic regression models were then used to determine the strength of association between the socio-demographic characteristics and knowledge on rabies and vaccination of dogs. All statistical analyses were considered significant at $p$-value $<0.05$. The results were then presented in tables and graphs.

\subsection{Ethical Issues}

Ethical approval was obtained from the University of Health and Allied Sciences (UHAS) Research Ethics Committee (UHAS-REC) (UHAS-REC A.6 [14] 17-18). Permission was also sought from the Upper East Regional Health Directorate and the municipal/district health directorates where data were collected. A written informed consent was obtained from the participants and confidentiality and anonymity were assured.

\section{Results}

\subsection{Socio-Demographic Characteristics of Respondents}

Out of the total number of 260 respondents, $186(71.5 \%)$ of them were males and $122(46.9 \%)$ were without any form of formal education. Most 190 (73.1\%) were married, with farming being the predominant occupation $(158,60.8 \%)$ amongst them (Table 1$)$. 
Table 1. Socio-demographic characteristics of respondents.

\begin{tabular}{|c|c|c|}
\hline Variable & Frequency $[n=260]$ & Percent $(\%)$ \\
\hline \multicolumn{3}{|l|}{ Age (In completed years) } \\
\hline$<20$ & 9 & 3.4 \\
\hline $20-29$ & 66 & 25.4 \\
\hline $30-39$ & 53 & 20.4 \\
\hline $40-49$ & 66 & 25.4 \\
\hline $50+$ & 66 & 25.4 \\
\hline \multicolumn{3}{|l|}{ Sex } \\
\hline Male & 186 & 71.5 \\
\hline Female & 74 & 28.5 \\
\hline \multicolumn{3}{|l|}{ Education } \\
\hline None & 122 & 46.9 \\
\hline Primary & 35 & 13.5 \\
\hline JHS & 30 & 11.5 \\
\hline SHS & 34 & 13.1 \\
\hline Tertiary & 39 & 15.0 \\
\hline \multicolumn{3}{|l|}{ Occupation } \\
\hline Unemployed & 31 & 11.9 \\
\hline Trader & 37 & 14.2 \\
\hline Farmer & 158 & 60.8 \\
\hline Civil/public servant & 34 & 13.1 \\
\hline \multicolumn{3}{|l|}{ Marital status } \\
\hline Never married & 51 & 19.6 \\
\hline Married & 190 & 73.1 \\
\hline Widowed & 19 & 7.3 \\
\hline
\end{tabular}

\subsection{Knowledge of Dog Owners on Rabies}

Table 2 presents the responses to various variables on awareness, transmission and treatment of rabies that were used to determine good and poor knowledge on rabies. Majority $214(82.3 \%) \mathrm{knew}$ that dogs were susceptible hosts of rabies, with $209(80.4 \%)$ also agreeing that dogs transmit rabies through bites and scratching. However, few $9(3.5 \%)$ knew that aggression, madness and paralysis were all signs of rabies. Majority $(195,75.0 \%)$ and $(7204,8.5 \%)$ also knew that rabies is preventable and that one has to go to the hospital for treatment after being bitten by a rabid dog respectively.

Table 2. Knowledge of dog owners about rabies.

\begin{tabular}{|c|c|c|}
\hline Variable & Frequency $(n)$ & Percentage $(\%)$ \\
\hline \multicolumn{3}{|c|}{ Do dogs carry rabies virus? $(n=260)$} \\
\hline Yes & 214 & 82.3 \\
\hline No & 46 & 17.7 \\
\hline \multicolumn{3}{|c|}{ Can a dog transmit rabies to human through biting or scratching? $(n=214)$} \\
\hline Yes & 208 & 97.2 \\
\hline No & 6 & 2.8 \\
\hline \multicolumn{3}{|c|}{ Can a dog transmit rabies to human through licking of open wounds? $(n=214)$} \\
\hline Yes & 33 & 15.4 \\
\hline No & 181 & 84.6 \\
\hline \multicolumn{3}{|c|}{ Are aggression, madness and paralysis all signs of rabies infection in humans? $(n=260)$} \\
\hline Yes & 9 & 3.5 \\
\hline No & 251 & 96.5 \\
\hline \multicolumn{3}{|c|}{ Can rabies be prevented? $(n=260)$} \\
\hline Yes & 195 & 75.0 \\
\hline No & 65 & 25.0 \\
\hline \multicolumn{3}{|c|}{ Is there the need to go to the hospital after being bitten by a dog? $(n=260)$} \\
\hline Yes & 204 & 78.5 \\
\hline No & 56 & 21.5 \\
\hline
\end{tabular}


Overall, we realized that 199 (76.5\%) of the dog owners had good knowledge on rabies, based on the criteria used.

\subsection{Association between Socio-Demographic Characteristics and Knowledge Level of Dog Owners on Rabies}

From Table 3, significant associations were found between dog owners' knowledge about rabies and district of residence $\left(\chi^{2}=112.59, p<0.001\right)$, sex $\left(\chi^{2}=6.14, p=0.013\right)$, education $\left(\chi^{2}=20.45\right.$, $p<0.001)$ as well as occupation $\left(\chi^{2}=11.97, p=0.007\right)$. Dog owners in the Bongo District (AOR $=6.74$, (95\% CI: 1.47, 30.89), $p=0.014)$ and the Bolga Municipality (AOR $=7.89,(95 \%$ CI: 1.49, 41.71) $p=0.015)$ were significantly more likely to have good knowledge compared to those in the Bawku Municipality. On the contrary, dog owners in the Kassena Nankana District were $96 \%$ significantly less likely to have good knowledge as compared to those in the Bawku (95\% CI: 0.01, 0.17, $p<0.001)$. Dog owners with tertiary level of education were also 76.31 times more likely (95\% CI: 6.20, 938.49, $p=0.001$ ) to have good knowledge on rabies compared to those with no formal education.

Table 3. Association between socio-demographic characteristics and knowledge about rabies.

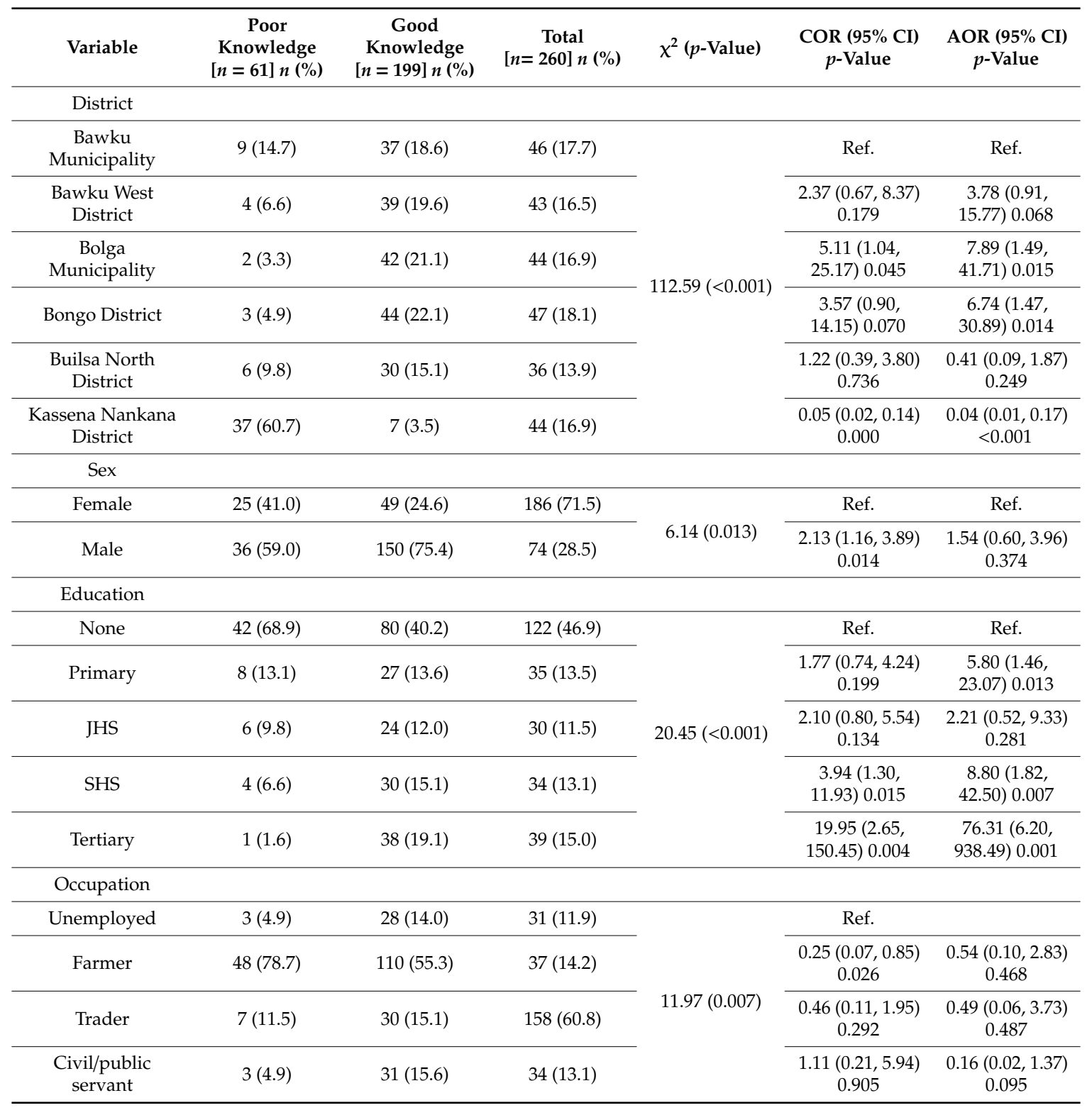




\subsection{Vaccination of Dogs by Owners against Rabies}

It was realized that $137(52.7 \%)$ of dog owners had currently (within a year at the time of data collection) vaccinated their dogs against rabies.

3.4.1. Association between Socio-Demographic Characteristics and the Vaccination of Dogs againts Rabies

Table 4 shows that there was a significant association between district $\left(\chi^{2}=57.61, p<0.001\right)$, level of educational attainment $\left(\chi^{2}=15.37, p=0.004\right)$, occupation, $\left(\chi^{2}=11.66, p=0.009\right)$, religion $\left(\chi^{2}=8.25\right.$, $p=0.016)$ and vaccination of dogs. Dog owners with tertiary level of education were more likely to vaccinate their dogs against rabies compared to those with no education (AOR $=3.57,95 \%$ CI: $0.97,13.14$ ).

Table 4. Association between socio-demographic characteristics and the vaccination of dogs against rabies and the odds of dog vaccination against rabies.

\begin{tabular}{|c|c|c|c|c|c|c|}
\hline Variable & \multicolumn{2}{|c|}{ Vaccinated Dog } & $\begin{array}{c}\text { Total } \\
{[n=260]} \\
n(\%)\end{array}$ & $\chi^{2}(p$-Value $)$ & $\begin{array}{c}\text { COR }(95 \% \text { CI }) \\
p \text {-Value }\end{array}$ & $\begin{array}{c}\text { AOR }(95 \% \mathrm{CI}) \\
p \text {-Value }\end{array}$ \\
\hline Bawku Municipal & $18(14.6)$ & $28(20.4)$ & $46(17.7)$ & \multirow{5}{*}{$57.61(<0.001)^{* *}$} & Ref. & \\
\hline Bawku West & $11(8.9)$ & $32(23.4)$ & $43(16.5)$ & & $1.87(0.76,4.63) 0.175$ & $5.27(1.73,16.03) 0.003$ \\
\hline Bongo & $17(13.8)$ & $30(21.9)$ & $47(18.1)$ & & $1.13(0.49,2.63) 0.768$ & $2.92(1.02,8.35) 0.045$ \\
\hline Builsa North & $11(8.9)$ & $25(18.2)$ & $36(13.9)$ & & $1.46(0.58,3.68) 0.421$ & $3.31(1.02,10.71) 0.046$ \\
\hline Kassena Nankana & $42(34.2)$ & $2(1.5)$ & $44(16.9)$ & & $0.03(0.01,0.14) 0.000$ & $0.06(0.11,0.29) 0.001$ \\
\hline \multicolumn{7}{|l|}{ Education } \\
\hline None & $68(55.3)$ & $54(39.4)$ & $122(46.9)$ & \multirow{3}{*}{$15.37(0.004)^{* *}$} & Ref. & Ref. \\
\hline SHS & $18(14.6)$ & $16(11.7)$ & $34(13.1)$ & & $1.12(0.52,2.40) 0.772$ & $0.62(0.23,1.65) 0.334$ \\
\hline Tertiary & $8(6.5)$ & $31(22.6)$ & $39(15.0)$ & & $4.88(2.07,11.48) 0.000$ & $3.57(0.97,13.14) 0.056$ \\
\hline \multicolumn{7}{|l|}{ Occupation } \\
\hline Unemployed & $14(11.4)$ & $17(12.4)$ & $31(11.9)$ & \multirow{4}{*}{$11.66(0.009)^{* *}$} & Ref. & Ref. \\
\hline Farmer & $86(69.9)$ & $72(52.5)$ & $158(60.8)$ & & $0.69(0.32,1.49) 0.346$ & $1.07(0.41,2.77) 0.891$ \\
\hline Trader & $15(12.2)$ & $22(16.1)$ & $37(14.2)$ & & $1.21(0.46,3.17) 0.701$ & $3.37(0.94,12.06) 0.062$ \\
\hline $\begin{array}{c}\text { Civil/public } \\
\text { servant }\end{array}$ & $8(6.5)$ & $26(19.0)$ & $34(13.1)$ & & $2.68(0.93,7.74) 0.069$ & $1.25(0.32,4.87) 0.752$ \\
\hline \multicolumn{7}{|l|}{ Religion } \\
\hline
\end{tabular}

3.4.2. Association between Awareness and Knowledge on Rabies and the Vaccination of Dogs against Rabies

There was a significant association between hearing about rabies, having good knowledge aboutrabies and vaccination of dogs against rabies $\left(\chi^{2}=46.25, p<0.001\right)$ and $\left(\chi^{2}=42.13, p<0.001\right)$ respectively (Table 5). Dog owners who had heard of rabies were 12 times more likely to vaccinate their dogs against the disease compared to those who had never heard of it (95\% CI: 2.54, 59.15, $p=0.002$ ). Even though not statistically significant, dog owners with good knowledge on rabies were more likely to vaccinate their dogs against rabies compared to those with poor knowledge [AOR $=1.99(95 \% \mathrm{CI}$ : $0.68,5.86), p=0.210]$. 
Table 5. Association between awareness and knowledge on rabies and the vaccination of dogs against rabies and the odds of dog vaccination.

\begin{tabular}{|c|c|c|c|c|c|c|}
\hline \multirow[b]{2}{*}{ Variables } & \multicolumn{2}{|c|}{ Vaccinated Dog } & \multirow[b]{2}{*}{$\begin{array}{c}\text { Total }[n=260] \\
\mathrm{n}(\%)\end{array}$} & \multirow[b]{2}{*}{$\chi^{2}(p$-Value $)$} & \multirow[b]{2}{*}{$\begin{array}{c}\text { COR }(95 \% \mathrm{CI}) \\
p \text {-Value }\end{array}$} & \multirow[b]{2}{*}{$\begin{array}{c}\text { AOR }(95 \% \mathrm{CI}) \\
p \text {-Value }\end{array}$} \\
\hline & $\begin{array}{c}\text { No }[n=123] \\
\text { n (\%) }\end{array}$ & $\begin{array}{c}\text { Yes }[n=137] \\
\text { n (\%) }\end{array}$ & & & & \\
\hline \multicolumn{7}{|c|}{ Ever heard of rabies } \\
\hline No & $42(34.1)$ & $3(2.2)$ & $45(17.3)$ & \multirow{2}{*}{$46.25(<0.001)$} & Ref. & Ref. \\
\hline Yes & $81(65.9)$ & $134(97.8)$ & $215(82.7)$ & & $23.16(6.95,77.15)<0.001$ & $12.25(2.54,59.15) 0.002$ \\
\hline \multicolumn{7}{|c|}{ Knowledge on rabies } \\
\hline Poor & $51(41.5)$ & $10(7.3)$ & $61(23.5)$ & \multirow{2}{*}{$42.13(<0.001)$} & Ref. & Ref. \\
\hline Good & $72(58.5)$ & $127(92.7)$ & $199(76.5)$ & & $9.0(4.31,18.80)<0.001$ & $1.99(0.68,5.86) 0.210$ \\
\hline
\end{tabular}

\section{Discussion}

The findings in this study revealed that the majority of dog owners $(76.5 \%)$ had good knowledge on rabies, its cause, symptoms, effects and prevention of the disease. Contrary to our findings other studies conducted in Ethiopia [23] and Tanzania [26] found knowledge about rabies to be $49.5 \%$ and $37 \%$ which were respectively much lower. The high level of knowledge we observed could be attributed to the fact that since the Upper East Region is a region where dogs are openly sold on the market for human consumption [15], a lot of the population was probably familiar with domestic dogs, including diseases like rabies that could be contracted from their handling and consumption.

On whether dogs were vaccinated against rabies, $52.7 \%$ of the respondents answered in the affirmative. Thus, the good knowledge about rabies demonstrated by the respondents did not translate into adoption of desirable preventive measures against the disease. Considering the high fatality rate of rabies, the reported percentage of dog vaccination is not encouraging [7,16]. Moreover, the American Animal Hospital Association's 2017 canine vaccination guidelines mentioned rabies vaccine as a core vaccine for dogs in rabies endemic regions such as Ghana. Thus, it is a requirement for every dog in such regions or countries to be vaccinated against rabies within the first six months of life. They then need a booster one year after the first vaccination and thereafter, should be vaccinated every three years. However, it is recommended that dogs be vaccinated on a yearly basis in regions where rabies is endemic [27]. Hence, the percentage rabies vaccination coverage found in this study, was woefully inadequate if rabies is to be controlled. Although there are no specific guidelines for dog vaccination against rabies in Ghana, according to Lopes et al., about $70 \%$ of the dog population in the country need to be vaccinated against rabies before a significant reduction in human rabies cases can be achieved [12]. However, the issue of low immunization of dogs against rabies is not peculiar to Ghana and specifically, the Upper East Region. Though higher than our recorded figure, dog vaccination against the disease has been reported to be below $80 \%$ in Brazil [28]. Comparing our finding to that of [28] affirms the low percentage vaccination of dogs in the Upper East Region of Ghana where dogs are not only kept as pets, but are also sold in the open market as meat. Considering the inhumane handling of dogs by both sellers and dog meat processors [29], one could easily be bitten by a dog that senses danger or feels distressed.

Our study further revealed that district of residence of dog owners influenced knowledge on rabies. Dog owners from Bolgatanga Municipality were for instance 7.89 times more likely to have good knowledge about rabies than those from Bawku Municipality. This result could be attributed to finding of the 2010 population and housing census where the Bolgatanga Municipality recorded the highest literacy rate (54.61\%) in the region [17]. Thus, the high level of education probably translated into high knowledge on rabies since education has been noted as an important predictor of health literacy in the literature $[30,31]$ as well as our own findings.

The high level of knowledge on rabies in the Bolgatanga Municipality did not translate into the practice of vaccinating dogs against rabies in the municipality. We found that residents of the municipality were $29 \%$ less likely to vaccinate their dogs against rabies as compared to the reference 
group, Bawku Municipality. In trying to understand knowledge, attitude and practice about dog bite and rabies exposure among dog meat consumers and processors in Abia State, Nigeria [29], found that although dog meat eaters and processors were very knowledgeable about rabies $(73.7 \%$ and $71.6 \%$ respectively), they did not consider rabid dogs to be of public health concern. Instead, they associated these dogs with medicinal and spiritual values, where some parts of rabid dogs were deemed capable of healing ailments such as malaria, enhancement of libido and spiritual protection. Thus, although residents of Bolgatanga Municipal were knowledgeable about rabies, they might not have been vaccinating their dogs against the disease as they might not have considered it to be of public health concern or are likely to have their own beliefs and perceptions of rabies and rabid dogs.

Sex was also found to be associated with knowledge on rabies. Male dog owners were for instance 1.5 times more likely to have good knowledge on rabies than females. Our finding is consistent with a study conducted by [32] who found that on the average, few women $(4.1 \%)$ are knowledgeable about the mode of transmission of some selected zoonotic diseases, including rabies. Thus, although knowledge acquisition is positively skewed in favour of women under equal socio-environmental conditions [33-36], it is not the case in the Bolga Municipality when it comes to knowledge on zoonotic diseases such as rabies. However, the low knowledge level of women on rabies in our study could be as a result of low interest in dog ownership among Ghanaian women in general [37] and in the Upper East Region in particular, as only $28.5 \%$ of our respondents were females. Thus, while American women are more likely to own dogs [38], that might not be the case in Ghana, especially in the Upper East Region. Hence, the less interest of females in the Upper East Region to own dogs might have affected their interest in knowing much about dogs and the diseases they transmit, such as rabies.

Occupation and religious affiliation of dog owners were found to significantly influence decision to vaccinate dogs against rabies. Dog owners who were traders, public and civil servants or farmers were respectively 3.4, 1.3 and 1.1 times more likely to vaccinate their dogs against rabies than those who were unemployed. Also, dog owners who were Muslims were 2.6 times more likely to vaccinate their dogs against rabies as compared to Christian dog owners. Moreover, dog owners who were traditionalists, which is an African way of understanding God and the world by believing in supernatural world of spirits and powers [39], were $4 \%$ less likely to vaccinate their dogs against rabies compared to Christians. According to the WHO [40], despite the introduction of Western medicine and healthcare systems in Africa, many Africans still rely on traditional medicine, often practiced by traditionalists. Most of these traditionalists thus do not believe in Western Medicine as they trust their supernatural powers to protect them from disease and illness and often attributes ill-health to a curse or punishment from the supernatural world [41]. Hence, they are likely not to blame rabies on dogs but see it as a misfortune or punishment from the spiritual world. As a result, traditionalists are less likely to vaccinate their dogs against rabies. The association between employment status and dog vaccination against rabies found in our study could be explained by the fact that rabies vaccine is administered at a cost to the dog owner as there are no funds for free vaccination of dogs in Ghana [42]. Hence dog owners who are unemployed may be reluctant to vaccinate their dogs against the disease as they may not be able to afford the cost of the vaccine. This has been explained by [43] that socio-economic conditions of individuals influence their health seeking decisions and behaviour.

The higher likelihood of Muslims vaccinating their dogs against Christian dog owners could be as a result of their faith. Islam does not require treatment to be provided to a Muslim patient if it merely prolongs the span of a terminal illness [44]. Buttressing this assertion, [45] explained that Islam attached significant importance to health; as such taking care of oneself is a religious duty. Hence, with such belief systems and the fatality of rabies in mind, Muslim dog owners might find it appropriate to vaccinate their dogs so as to prevent the case of managing a fatal illness like rabies by vaccinating their dogs against it to protect their much-cherished good health as a religious obligation.

Our study found that educational level significantly influenced knowledge of dog owners on rabies. Dog owners who had tertiary education had higher odds of having good knowledge on rabies and vaccinating their dogs against it than those with no formal education. Hence, high level of 
education of dog owners translated into good vaccination practices of dogs against rabies. Moreover, we found that dog owners who ever heard of rabies were 12.3 times more likely to vaccinate their dogs against the disease than those who did not. This is not surprising as education has been noted as an important predictor of health decision making [46]. This finding is consistent with studies done in Tanzania and Pakistan where respondents with secondary and tertiary education were associated with having better knowledge of rabies $[47,48]$. Therefore, awareness creation and education on rabies among dog owners is should be encouraged among dog owners in the Upper East Region of Ghana to improve vaccination of dogs against the diseases. This could be achieved by training and awarding of certificates to individuals such as unemployed graduates, to becoming active members by educating communities about rabies, as is the case in South Africa, Lesotho Zimbabwe and Mozambique [49]. Furthermore, village chiefs, community leaders, traditional healers and teachers could be engaged in rabies awareness and information counseling as they are more trusted in their communities than health workers and veterinary officers who are most often not indigenous community members. Also, awareness campaigns could target school children through development, dissemination and usage of children's rabies awareness booklets to be used by teachers in schools as part of the school curriculum to educate children on the prevalence, symptoms effects and prevention methods on rabies in schools, as in the case of Zimbabwe [49].

\section{Limitations of the Study}

Despite the important findings we made in this study, the limitations of the study are worth noting. One of the limitations with this study is the non-inspection of vaccination certificates of the dog owners. We believe that this could have corroborated the self-reports given by the participants regarding their vaccination of the dogs and added more value to the study.

Also, since our study was cross sectional in nature, we did not establish unobserved heterogeneity. Thus, a causal relationship could not be established between dog vaccination and knowledge as well as factors identified other than, an association. Also, the associations observed between the outcome and explanatory variables could also vary over time. Moreover, the high level of knowledge we recorded could be as a result of the wording of some of the questions which potentially led respondents to the correct answers. Thus, the knowledge level could have been lower if more neutral questions were asked. Lastly, we did not collect data on respondents' income status, hence could not fully explore the role socio-economic status could play in influencing decisions on dogs' vaccination against rabies.

\section{Conclusions}

Level of knowledge about rabies was found to be associated with the district of residence, sex, educational level as well as occupation of dog owners. District of residence, educational level, occupation, religion and knowledge on rabies also had significant association with dog vaccination against rabies. Given that dog owners in the Upper East Region of Ghana had good knowledge about rabies, but this did not translate into correspondingly high levels of dog vaccination against the disease, we recommend that rabies awareness and vaccination campaigns should be intensified in the region, especially among the least educated and female dog owners. Also, future studies should take into consideration the role of socio-economic status in influencing anti-rabies dog vaccination decisions in the region.

Author Contributions: B.A. and M.K. conceived the study, B.A., M.K., S.A.Z., S.A.B. and M.A. did the data analysis and wrote the methods section. B.A., M.K., M.A., H.A., E.M., M.A.A., F.Y.A., and E.T. were responsible for the initial draft of the manuscript. All authors reviewed and approved the final version of the manuscript.

Funding: This research received no external funding.

Acknowledgments: We are grateful to the staff of the School of Public Health Research Laboratory, University of Health and Allied Sciences. We are also grateful to the staff of all the participating health facilities and the Veterinary Service Division of the Upper East Region. We would like to thank Tanko Abdul-Razak, the District 
Disease Control Officer, Jasikan District, staff of the Regional Disease Control Unit of the Upper East Region, the interviewers and the dog owners who participated in the study.

Conflicts of Interest: The authors declare no conflict of interest.

\section{References}

1. Oxley, J.A.; Christley, R.; Westgarth, C. Contexts and consequences of dog bite incidents. J. Vet. Behav. 2018, 23, 33-39. [CrossRef]

2. Bizri, A.; Alawieh, A.; Ghosn, N.; Berry, A.; Musharrafieh, U. Challenges facing human rabies control: The Lebanese experience. Epidemiol. Infect. 2014, 142, 1486-1494. [CrossRef] [PubMed]

3. Salomão, C.; Nacima, A.; Cuamba, L.; Gujral, L.; Amiel, O.; Baltazar, C.; Gudo, E.S. Epidemiology, clinical features and risk factors for human rabies and animal bites during an outbreak of rabies in Maputo and Matola cities, Mozambique, 2014: Implications for public health interventions for rabies control. PLoS Negl. Trop. Dis. 2014, 11, e0005787. [CrossRef] [PubMed]

4. Bano, I.; Sajjad, H.; Shah, A.M.; Leghari, A.; Mirbahar, K.H.; Shams, S.; Soomro, M. A review of rabies disease, its transmission and treatment. J. Anim. Health Prod. 2017, 4, 140-144. [CrossRef]

5. World Health Organization. WHO Expert Consultation on Rabies: Second Report WHO Technical Report. Series 982. 2013. Available online: http://apps.who.int/iris/bitstream/10665/85346/1/9789240690943_eng.pdf (accessed on 3 January 2019).

6. Hampson, K.; Coudeville, L.; Lembo, T.; Sambo, M.; Kieffer, A.; Attlan, M.; Costa, P. Estimating the global burden of endemic canine rabies. PLoS Negl. Trop. Dis. 2015, 9, e0003709.

7. World Health Organization. Rabies: Key Facts. 2018. Available online: http://www.who.int/news-room/factsheets/detail/rabies (accessed on 27 February 2019).

8. Apanga, P.A.; Awoonor-Williams, J.K.; Acheampong, M.; Adam, M.A. A presumptive case of human rabies: A rare survived case in rural Ghana. Front. Publ. Health 2016, 4, 256. [CrossRef] [PubMed]

9. Ministry of Food and Agriculture, Veterinary Services Directorate (VSD) in 2011. Available online: http: //mofa.gov.gh/site/?page_id=10049 (accessed on 13 April 2018).

10. Elieza, S. Trends in Dog Bites and Human Rabies in Greater Accra Region, Ghana. Master's Thesis, University of Ghana, Legon, Accra, Ghana, 2016. Available online: http://ugspace.ug.edu.gh/handle/123456789/8470 (accessed on 10 January 2018).

11. Hayman, D.T.S.; Johnson, N.; Horton, D.L.; Hedge, J.; Wakeley, P.R.; Banyard, A.C.; Zhang, S.; Alhassan, A.; Fooks, A.R. Evolutionary history of rabies in Ghana. PLoS Negl. Trop. Dis. 2011. [CrossRef]

12. Lopes, P.H.; Akweongo, P.; Wurapa, F.; Afari, E.; Sackey, S.O.; Hansen, E.M.; Nyarko, K.M. Canine Rabies outbreaks, vaccination coverage, and transmission in humans: Greater Accra Region, Ghana-A retrospective study-2006-2011. Am. J. Clin. Exp. Med. 2018, 6, 58-63. [CrossRef]

13. Ghana Statistical Service. Ghana-Ghana Living Standard Survey. 2017. Available online: http://www2. statsghana.gov.gh/nada/index.php/catalog/97/study-description (accessed on 24 February 2019).

14. Belcher, D.W.; Wurapa, F.K.; Atuora, D.O.; Public, S.; Angeles, L. Endemic rabies in Ghana. Epidemiology and control measures. Am. J. Trop. Med. Hyg. 1976, 25, 724-729. [CrossRef]

15. Brown, M. Ghana, Africa: Bolga's Live Dog Meat Market. 2017. Available online: https://fightdogmeat.com/ 2017/01/26/ghana-africa-bolgas-live-dog-meat-market/ (accessed on 10 March 2019).

16. Adomako, B.Y.; Baiden, F.; Sackey, S.; Ameme, D.K.; Wurapa, F.; Nyarko, K.M.; Afari, E. Dog Bites and Rabies in the Eastern Region of Ghana in 2013-2015: A Call for a One-Health Approach. J. Trop. Med. 2018, 2018, 6139013. [CrossRef]

17. Laryea, D.O.; Owusu, R.; Arthur, J.; Opambour, E.A.; Spangenberg, K. Human Rabies in Kumasi: A Growing Public Health Concern. Afr. J. Curr. Med. Res. 2017, 1, 1-4. [CrossRef]

18. Ghana Statistical Service, 2010 Population and Housing Census: Regional Analytical Report, Upper East Region, 2013. Available online: http://www.statsghana.gov.gh/docfiles/2010phc/2010_PHC_Regional_ Analytical_Reports_Upper_East\%20Region.pdf (accessed on 11 November 2018).

19. Setia, M.S. Methodology Series Module 3: Cross-sectional Studies. Indian J. Dermatol. 2016, 61, $261-264$. [CrossRef] [PubMed]

20. Mathers, N.; Fox, N.; Hunn, A. Surveys and questionnaires. In The NIHR RDS for the East Midlands/Yorkshire $\mathcal{E}$ the Humber; National Institute for Health Research: Sheffield, UK, 2007. 
21. Cochran, W.G. Sampling Techniques, 3rd ed.; John Wiley \& Sons: New York, NY, USA, 1977.

22. World Health Organization. Training for Mid-Level Managers, Module 7: The Epic Coverage Survey. 2008. Available online: http://apps.who.int/iris/bitstream/handle/10665/70184/WHO_IVB_08.07_eng.pdf? sequence $=7$ (accessed on 18 December 2018).

23. Assefa, A.; Alie, A.; Derso, S.; Ayele, B. Assessment of knowledge, attitude and practice on rabies in and around Debretabor, South Gondar, Northwest Ethiopia. Int. J. Basic Appl. Virol. 2015, 4, 28-34. [CrossRef]

24. Taber, K.S. The use of Cronbach's alpha when developing and reporting research instruments in science education. Res. Sci. Educ. 2018, 48, 1273-1296. [CrossRef]

25. Sima, B.T.; Belachew, T.; Abebe, F. Health care providers' knowledge, attitude and perceived stigma regarding tuberculosis in a pastoralist community in Ethiopia: A cross-sectional study. BMC Health Serv. Res. 2019, 19, 19. [CrossRef]

26. Sambo, M.; Lembo, T.; Cleaveland, S.; Ferguson, H.M.; Sikana, L.; Simon, C.; Urassa, H.; Hampson, K. Knowledge, attitudes and practices (KAP) about rabies prevention and control: A community survey in Tanzania. PLoS Negl. Trop. Dis. 2014, 8, e3310. [CrossRef] [PubMed]

27. Ford, R.B.; Larson, L.J.; Schultz, R.D. 2017 AAHA Canine Vaccination Guidelines. 2017. Available online: https://www.aaha.org/globalassets/02-guidelines/canine-vaccination/vaccination_recommendation_ for_general_practice_table.pdf (accessed on 6 August 2019).

28. Rodrigues, R.C.A.; von Zuben, A.P.B.; de Lucca, T.; Reichmann, M.A.B. Rabies vaccination campaigns in dogs and cats, and rabies positivity in bats, from 2004 to 2014, in Campinas, São Paulo, Brazil. Epidemiol. Serv. Saude Bras. 2017, 26, 621-628. [CrossRef]

29. Mshelbwala, P.; Ogunkoya, A.; Maikai, B.V.; Atuman, S. Knowledge, Attitude and Practice about Dog Bite and Rabies Exposure among Dog Meat Consumers and Processors in Abia State, Nigeria. J. Vet. Adv. 2014, 4, 398. [CrossRef]

30. Nutbeam, D. Health literacy as a public health goal: A challenge for contemporary health education and communication strategies into the 21st century. Health Promot. Int. 2000, 15, 259-267. [CrossRef]

31. Cho, Y.I.; Lee, S.Y.; Arozullah, A.M.; Crittenden, K.S. Effects of health literacy on health status and health service utilization amongst the elderly. Soc. Sci. Med. 2008, 66, 1809-1816. [CrossRef]

32. Patel, K.; Saxena, D. Self-reported selected zoonotic diseases among animal handlers in Urban Ahmedabad, India. Vet. World 2019, 12, 176-182. [CrossRef]

33. Schumm, M.F.; Bogner, F.X. How Environmental attitudes interact with cognitive learning in a science lesson module. Educ. Res. Int. 2016, 1-7. [CrossRef]

34. Frosslin, J.; Norman, M. Differing perceptions-Swedish farmers' views of infectious disease control. Vet. Med. Sci. 2016, 2, 54-68. [CrossRef]

35. Figurska, I.; Sokol, A. The process of knowledge acquisition with the use of various teaching methods and its effect on the creativity of employees of the creative Sector. Mediterr. J. Soc. Sci. 2016, 7, 143-151. [CrossRef]

36. Young, M.R. Knowledge acquisition and readiness assurance testing: The connected notes intervention. J. Mark. Educ. 2016, 38, 145-156. [CrossRef]

37. Amissah-Reynolds, P.K.; Monney, I.; Adowah, L.M.; Agyemang, S.O. Prevalence of Helminths in Dogs and Owners' Awareness of Zoonotic Diseases in Mampong, Ashanti, Ghana. J. Parasitol. Res. 2016, 1-6. [CrossRef]

38. Saunders, J.; Parast, L.; Babey, S.H.; Miles, J.V. Exploring the differences between pet and non-pet owners: Implications for human-animal interaction research and policy. PLoS ONE 2017, 12, e0179494. [CrossRef]

39. Kritzinger, J.J. Mission in an African Way. A practical introduction to African Instituted Churches and their sense of mission, Thomas Oduro, Hennie Pretorius, Stan Nussbaum and Bryan Born: Book review. Missionalia South. Afr. J. Mission Stud. 2009, 37, 137-139.

40. World Health Organization. Legal Status of Traditional Medicine and Complementary/Alternative Medicine: Worldwide Review; WHO: Geneva, Switzerland, 2001.

41. Benedict, A.O. The perception of illness in traditional Africa and the development of traditional medical practice. Int. J. Nurs. 2014, 1, 51-59.

42. Ghana News Agency. Veterinarian Advises Public to Treat Animal Bites Properly to Prevent Rabies Infection; Ghana News Agency: Accra, Ghana, 2012. Available online: http://www.ghananewsagency.org/health/veterinarianadvises-public-to-treat-animal-bites-properly-to-prevent-rabies-infection-38369 (accessed on 12 June 2019). 
43. Musinguzi, G.; Anthierens, S.; Nuwaha, F.; Van Geertruyden, J.; Wanyenze, R.K.; Bastiaens, H. Factors Influencing Compliance and Health Seeking Behaviour for Hypertension in Mukono and Buikwe in Uganda: A Qualitative Study. Int. J. Hypertens. 2018, 8307591. [CrossRef]

44. State of Queensland. Health Care Providers' Handbook on Muslim Patients, 2nd ed.; Queensland Government: Kedron, Australia, 2010. Available online: https://www.health.qld.gov.au/_data/assets/pdf_file/0034/155887/ islamgde2ed.pdf (accessed on 16 June 2019).

45. Attum, B.; Shamoon, Z. Cultural Competence in the Care of Muslim Patients and Their Families. In StatPearls [Internet]; StatPearls Publishing: Treasure Island, FL, USA, 2019. Available online: https://www.ncbi.nlm.nih. gov/books/NBK499933/ (accessed on 13 March 2019).

46. Kazadi, E.K.; Tshilenge, G.M.; Mbao, V.; Njoumemi, Z.; Masumu, J. Determinants of dog owner-charged rabies vaccination in Kinshasa, Democratic Republic of Congo. PLoS ONE 2017, 12, e0186677. [CrossRef]

47. Sambo, M.B. Epidemiological Dynamics of Rabies in Tanzania and Its Impacts on Local Communities. 2012. Available online: http://scholar.google.com/scholar?hl=en\&q=+Epidemiological+dynamics+of+rabies+in+ Tanzania+and+its+impacts+on+local+communities (accessed on 30 August 2018).

48. Wasay, M.; Malik, A.; Fahim, A.; Yousuf, A.; Chawla, R.; Daniel, H.; Rafay, M.; Azam, I.; Razzak, J. Knowledge and attitudes about tetanus and rabies: A population-based survey from Karachi, Pakistan. J. Pakistan Med. Assoc. 2012, 62, 378-382.

49. World Health Organization. Driving Progress towards Rabies Elimination: New WHO Recommendations on Human Rabies Immunization and Results of Gavi's Learning Agenda on Rabies and 2nd International Meeting of the Pan-African Rabies Control Network (PARACON): Meeting Report, Johannesburg, South Africa (No. WHO/CDS/NTD/NZD/2019.02), 12-14 September 2018; World Health Organization: Geneva, Switzerland, 2019.

(C) 2019 by the authors. Licensee MDPI, Basel, Switzerland. This article is an open access article distributed under the terms and conditions of the Creative Commons Attribution (CC BY) license (http://creativecommons.org/licenses/by/4.0/). 